
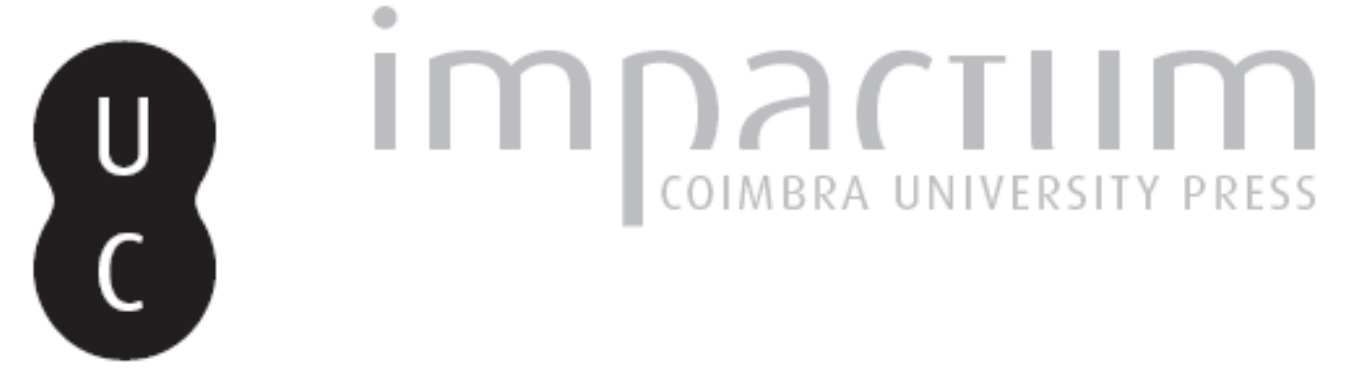

\title{
Fornos de ânforas romanas na bacía do rio Sado: Pinheiro, Abul e Bugio
}

Autor(es): $\quad$ Cardoso, Guilherme

Publicado por: Imprensa da Universidade de Coimbra

URL persistente:

URl:http://hdl.handle.net/10316.2/45616

DOI:

DOI:https://dx.doi.org/10.14195/1647-8657_25_10

Accessed : $\quad$ 26-Apr-2023 14:09:25

A navegação consulta e descarregamento dos títulos inseridos nas Bibliotecas Digitais UC Digitalis, UC Pombalina e UC Impactum, pressupõem a aceitação plena e sem reservas dos Termos e Condições de Uso destas Bibliotecas Digitais, disponíveis em https://digitalis.uc.pt/pt-pt/termos.

Conforme exposto nos referidos Termos e Condições de Uso, o descarregamento de títulos de acesso restrito requer uma licença válida de autorização devendo o utilizador aceder ao(s) documento(s) a partir de um endereço de IP da instituição detentora da supramencionada licença.

Ao utilizador é apenas permitido o descarregamento para uso pessoal, pelo que o emprego do(s) título(s) descarregado(s) para outro fim, designadamente comercial, carece de autorização do respetivo autor ou editor da obra.

Na medida em que todas as obras da UC Digitalis se encontram protegidas pelo Código do Direito de Autor e Direitos Conexos e demais legislação aplicável, toda a cópia, parcial ou total, deste documento, nos casos em que é legalmente admitida, deverá conter ou fazer-se acompanhar por este aviso.

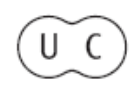


FACULDADE DE LETRAS

INSTITUTO DE ARQUEOLOGIA

CONIMBRIGA

$V O L U M E X X V$

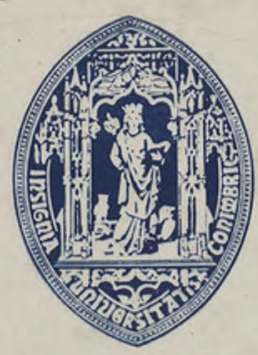

UNIVERSIDADE DE COIMBRA

1986 
Gabinete de Arqueologia do Município de Cascais

FORNOS DE ÂNFORAS ROMANAS NA BACIA DO RIO SADO:

PINHEIRO, ABUL E BUGIO

«Conimbriga», XXV (1986), p. 153-173

Resumo: Apresenta-se um conjunto de ânforas romanas recolhidas nos fornos da bacia do Sado, em 1976. Além das formas mais comuns, o autor identifica tipologías para que não encontrou paralelos, designando-os, pois, de formas 91, 92, 93 e 94.

Résumé Étude descriptif d'un ensemble d'amphores romaines trouvées dans les fours du bassin du fleuve Sado, aux environs d'Alcâcer do Sal (la Salada romaine). On y rencontre des formes communes, mais l'Auteur identifie des typologies sans parallèle connu, qu'il désigne formes 91, 92, 93 e 94. 
(Página deixada propositadamente em branco) 


\section{FORNOS DE ÂNFORAS ROMANAS NA BACIA DO RIO SADO: PINHEIRO, ABUL E BUGIO *}

Serve o presente trabalho para apresentar um conjunto de ânforas romanas recolhidas por nós e por elementos do Museu do Mar (Cascais) nos fornos da bacia do Sado, durante o ano de 1976.

Sobre estas ânforas pudemos já tecer algumas considerações nas III Jornadas Arqueológicas da Associação dos Arqueólogos Portugueses, em 1976. E, num artigo publicado em 1978 (*), apresentámos também alguns aspectos do tema que ora nos vai ocupar.

Foi no III Colóquio de Setúbal (1975), onde expusemos um trabalho sobre outras ânforas do Museu do Mar, que ficou mais clara a importância dos fornos da bacia do Sado.

Justificava-se uma visita a estas jazidas — desconhecidas até à publicação de um pequeno artigo inserido n' $\ll 0$ Arqueólogo Português» ( $\left.{ }^{2}\right)$, da autoria de D. Fernando de Almeida e dos geólogos Georges Zbyzewski e O. da Veiga Ferreira-mais não fosse devido à falta de elementos que definissem as origens de uma grande parte das ânforas recolhidas no rio Sado, frente a Tróia, e que $\mathrm{o}$ artigo referido não elucidava na totalidade. A confusão

* Agradecemos ao Doutor Jorge de Alarcão a orientação científica que amavelmente nos deu e ao doutor José d'Encarnação a colaboração prestada na feitura deste artigo. Severino Rodrigues passou a limpo os desenhos, o Dr. Luís Pascoal procedeu à montagem das gravuras - para eles também o meu reconhecimento.

(9 Guilherme Cardoso, Anforas Romanas no Museu do Mar (Cascais), «Conimbriga», XVII, 1978, p. 63-78.

(2) Descoberta de Fornos Lusitano-Romanos na Região da Marateca (Setúbal), «O Arqueólogo Português», série III, V, 1971, p. 155-165. 
reinante sobre as diferentes formas fabricadas nesses fornos leva-nos a apresentar este estudo de materiais aí recolhidos, indicando as conclusões a que chegámos.

A cronologia adoptada baseia-se em dados expressos em artigos da especialidade, devido à falta de escavações em qualquer das jazidas e ao facto de os fragmentos identificáveis terem sido recolhidos a esmo dentro de valas de drenagem ou superficialmente, sem qualquer referêndia estratigráfica e poucas de contexto.

\section{Os Fornos}

\section{Herdade do Pinheiro}

Estes fornos, localizados na região da Marateca, já mereceram uma publicação sumária, em 1971, após a sua descoberta (3). São, até ao momento, dos mais importantes de que temos notícia, em território português, tanto pela quantidade de vestígios como pela diversidade de formas observadas. Funcionaram entre o séc. i d.C. e o séc. iv, chegando as camadas das entulheiras dos rejeitados a atingir dois metros de altura, desenvolvendo-se desde a zona terrestre dos fornos grandes, a nascente, para o lado do rio, a poente, morrendo nos arrozais que actualmente circundam a zona que, na época romana, era banhada pelo rio, hoje a uns 400 metros de distância.

Descortinámos, durante as nossas visitas ao local, a existência de uma identidade tipológica por zonas, sendo a mais próxima dos fornos grandes ocupada principalmente por ânforas da forma Dressel 14 e alguns fragmentos Almagro 50 nos estratos superiores. Entre esta zona e até perto dos arrozais a poente, só observámos vestígios da forma D. 14 e, por último, numa vala de drenagem que contorna os arrozais, a forma D. 14 escasseia, abundando as lusitanas, D. 30, Almagro 51 e, esporadicamente, Almagro 50, além de outros tipos mais raros.

(3) D. Fernando de Almeida e outros, art. cit. 
Herdade de Monte Novo - Abul

A 300 metros para poente do antigo monte de Abul, hoje abannado e pertença do Monte Novo, situa-se um pequeno cabeço junto ao rio Sado. O chão encontra-se juncado de cerâmica e, na vala de rega circundante ao cabeço, recolheram-se várias bocas de ânfora D. 14, que foram colocadas a descoberto durante a abertura da mesma.

Nos terrenos secos dos arrozais, a sul da vala de rega, apareceram fragmentos de ânforas D. 24 partidas pelo arado. $\mathrm{Na}$ praia, durante a vazante, observa-se grande quantidade de cerâmicas enterradas no lodo.

\section{Herdade do Bugio}

Situados a cerca de quatro quilómetros de Alcácer do Sal, na Herdade do Bugio, foram postos a descoberto a quando da montagem da linha do caminho-de-ferro de Setúbal para Alcácer.

Segundo informações obtidas, teriam sido achadas ânforas inteiras, prontamente partidas pelos cabouqueiros.

Dos fornos, a única coisa que se via, em 1976, era a parede lateral da câmara de cozedura no barranco sobre a linha férrea e, para norte, o chão encontrava-se coberto de tijolos, assinalando, possivelmente, a existência de outro forno. Deste forno já foi apresentada, em 1980, uma notícia preliminar da sua descoberta, por Dias Diogo, após a nossa comunicação às III Jornadas Arqueológicas, de $1977\left(^{4}\right)$.

$\left({ }^{4}\right)$ A. M. Dias Drogo, Fornos de Anforas do Monte do Bugio - Noticia Preliminar, «Conimbriga», XIX, 1980, p. 147-150. 


\section{As Formas}

\section{Forma D vessel 14 ;Beltran IV}

Forma vulgar em Portugal: encontraram-se olarias romanas com fabrico deste tipo de ânfora na bacia do Tejo(5) e em S. Bartolomeu de Castro Marim( $\left(^{6}\right)$; é o mais comum nos fornos da região do Sado. Aparece desde a Herdade da Barrosinha, em Alcácer do Sal, até à Quinta da Alegria, em Setúbal, mais ou menos semelhante na forma. Com cerca de um metro de altura, bojo entre cilíndrico e o ovoide, lábio saliente em pérola ou simplesmente liso, com pé em cone alto ou baixo, sempre oco, já conseguimos distinguir seis subtipos e mais distinguiríamos; só que é mais importante descrevermos as formas existentes em cada forno e deixar para mais tarde toda uma definição que apenas interessará verdadeiramente quando se conseguir datar com precisão cada uma das variantes. Estamos convencidos, aliás, de que não coexistem todas essas formas na mesma época.

Nas figuras 1 e 2, dos fornos do Pinheiro, distinguem-se as variantes de bordo perolado, variante II e III Beltrán ( ${ }^{7}$ ) e III, IV de Parker $\left.{ }^{8}\right)$, sendo datadas pelo primeiro como do séc. niii d.C. $\left({ }^{9}\right)$.

Outra variante, esta de bordo liso (Figs. 34 e 35 do forno de Abul e Fig. 44 e 45 dos fornos do Bugio), é idêntica à variante $\mathrm{V}$ Beltrán $\left({ }^{10}\right)$ e às variantes I e II de Parker ( $\left.{ }^{u}\right)$. Foram recolhidas

(5) Clementino a maro, Prospecção e Reconhecimento - Distrito de Santarém-fienav ente, «Informação Arqueológica», 3, 1980, p. 12-13.

(6) Manuel Main, as Anforas de S. Bartolomeu de Castro Marim, «Glio», 1, 1979, p. 141-144.

(7) M. Beltrán Lloris, Las Anforas Romanas en Espama, Zaragoza, 1970, p. 457.

(8) Anthony J. PArker, Lusitanian Amphoras, «Méthodes Classiques et Méthodes Formelles dans l'Étude des Amphores», Collection de 1'École Française de Rome, 32, 1977, p. 38.

(9) M. Beltrán Lloris, o. cit., p. 459.

(10) IDEM, p. 451.

(n) Anthony J. PARKer, o. cit., p. 38. 
idênticas na Herdade da Enchurrasqueira e Vale da Cepa $\left({ }^{12}\right)\left({ }^{13}\right)$, bem como nos fornos da Herdade da Barrosinha, em Alcácer, e na Quinta da Alegria $\left({ }^{14}\right)$. Esta forma apareceu em Óstia nos estratos atribuídos à época flávia e nos estratos tardo-antoninos $\left({ }^{15}\right)$. Pascual Guasche $\left({ }^{16}\right)$ data este fabrico dos finais do séc. i d.C. e grande parte do n. Nas escavações do castelo de Alcácer do Sal $\left({ }^{17}\right)$ e na cidade de Setúbal $\left({ }^{18}\right)$ este tipo de ânfora foi encontrado em estratos do séc. i e ii d.C.. Nós próprios recolhemos em Abul, junto aos fragmentos de boca (Figs. 34 e 35), um pedaço de bordo de sigillata hispânica da forma Drag. 37, de datação difícil de precisar (séc. ii-iii d.C.).

Das asas desta forma recolhemos um fragmento (Fig. 3) com a marca B.F., nos fornos do Pinheiro, e o fragmento de uma outra (Fig. 48) sem marca, nos fornos do Bugio.

Os pés são em bico oco, de forma fálica (Figs. 5, 6, 7 e 8 , do Pinheiro; Figs. 36, 40, 41 e 42, de Abul; e as Figs. 47, 48, 49 e 50, da Herdade do Bugio). A Fig. 8 é de um pé que tem esgrafitado um $\mathrm{P}$, idêntico a outro já recolhido nos mesmos fornos do Pinheiro ( ${ }^{19}$ ); um outro (Fig. 36) apresenta um grafito seme-

(12) A. M. Dias Diogo, Fornos de Anforas do Monte da Enchurrasqueira e do Vale da Cepa - Notícia Preliminar, «Conimbriga», XXII, 1983, p. 209-215.

(13) A. M. Dias Diogo, A. G. de Carvalho, I. M. de Sá Rebelo, J. M. Leiria Fernandes e M. F. Garcia Rollo, O Material dos Fornos Romanos da Enchurrasqueira no Museu do Mar - Cascais, «Série Arqueológica do Museu do Mar», 3, 1984.

(14) A. Coenho-Sonres e Tavares da Silva, Anforas Romanas da Quinta da Alegria (Setúbal), «Setúbal Arqueológica», V, 1979, p. 211-212.

$\left({ }^{\circ}\right)$ C. Panella, Annotazioni in Margine Alie Stratigrafie delle Terme Ostiensi del Nuotatore - Recherches sur les Amphores Romaines, Collection de l'École Française de Rome, 10, 1972, p. 82.

(16) Ricardo Pascual Guasch, El pecio Randofo (AImeria), «Pyrenae», 4, 1968, p. 146.

(17) C. Tavares da Silva, Joaquina Soares, C. Mello Beirão, L. Ferrer Dias e A. Coenho-Sonres, Escavações Arqueológicas no Castelo de Alcácer do Sal (Campanha de 1979), «Setúbal Arqueológica», VI-VII, 1980/81, p. 197.

(18) C. Tavares da Silva e Antonia Coenho-Sonres, A Praça do Rocage (Setúbal) na Época Romana. Escavações Arqueológicas de 1980, «Setúbal Arqueológica», VI-VII, 1980/81, p. 253-254.

(19) D. Fernando de Almeid A e outros, art. cit., Est. VII. 
lhante a uma seta. São comuns, pelo que pensamos que indicam a quantidade de produção de um oleiro.

\section{Forma Dressel $24\left({ }^{20}\right)$}

Foram recolhidos dois fragmentos desta forma na Herdade de Abul (Figs. 37 e 38); aparentadas com a D. 14 (21), estas ânforas são, no entanto, de porte mais pequeno. Dos fragmentos que recolhemos temos um bordo, semi-perolado, com encaixe interno para opérculo, e um fragmento de colo com asas em fita de nervura central em relevo, diferente do sulco habitual na D. 14 .

Este tipo é atribuído por Dressel ao séc. i d.C. e aos sécs. ii-m, por Lamboglia (22). O seu conteúdo é desconhecido, podendo pensar-se na sua utilização para levar pasta de peixe.

$\left({ }^{20}\right)$ Sobre esta classificação cumpre-nos transcrever uma passagem do trabalho citado na nota 13 :

«(...) No que respeita a ânforas, os fornos de Abul aparentam apenas ter produzido Dresdel 14; a informação de Guilherme Cardoso sobre a produção de ânforas Dressel 24, baseia-se na classificação errada do nosso exemplar n. ${ }^{\circ}$ : o fragmento superior de uma ânfora Dressel 14, de bordo perolado e boca esvasada».

Desconhecemos onde é que os autores poderão ter colhido a citada «informação», pois o trabalho agora publicado estava inédito, apenas tendo sido apresentado na comunicação feita em 1977 por ocasião das III Jornadas Arqueológicas, como atrás dissemos.

Os autores não esclarecem em que circunstâncias tomaram conhecimento dessa hipotética informação, o que lamentamos, devido à confusão que pode gerar.

(21) O lábio difere do da forma que habitualmente se considera como sendo Dressel 24 (Guilherme Cardoso, art. cit., p. 70). É, contudo, o tipo que apresentamos aquele que melhor condiz com o da tabela Dressel.

(22) Fausto ZEvi, Appunti sulle Anfore Romane, «Archeologia Classica», XVIII, 1966, p. 223. 


\section{Forma Dressel 28/Oberaden 74}

A Fig. 4 representa um fragmento desta forma achado nos fornos do Pinheiro. Encontra-se em muito mau estado de conservação; a pasta está a desagregar-se, principalmente nas asas, não permitindo ver correctamente o corte, que podia ser idêntico à forma 24, fabricada em Abul, e que é também semelhante às ânforas descobertas em Oberaden (23).

Loeschke $\left({ }^{24}\right)$ considera-as datáveis desde a segunda metade do séc. i a.C. até meados do séc. i d.C., usadas para conter vinho. Dressel (25), pelo contrário, data-as da segunda metade do séc. i d.C., e é de opinião de que serviam para garum.

\section{Forma Dressel 301 Anfora lusitana}

Como afirmámos no nosso anterior trabalho $\left({ }^{26}\right)$, não podemos atribuir, sem mais, a esta ânfora a forma D. 30, se bem que lhe seja muito semelhante em alguns casos, como, por exemplo, a boca procedente da Quinta da Alegria descrita com o n. $30\left({ }^{27}\right)$, e a peça n. ${ }^{\circ} 37$ da Herdade da Enchurrasqueira (28), que tem um perfil idêntico ao apresentado por Dressel na sua tabela.

Existe entre esta forma e a Almagro $51 \mathrm{C}$ uma grande semelhança, distinguindo-se principalmente pela inclinação das asas e pela maior largura do bojo.

São deste tipo os fragmentos representados nas Figs 9, 10, 11, 13 e 33 do Pinheiro, sendo o n. 9 uma variante de bordo triangular e o ${ }^{\circ}{ }^{\circ} 11$ uma variante de bordo saliente em fita.

(23) Loeschке, Das Rõmerlage in Oberaden, II, Dortmund, 1942, grav. 31.

(24) LOESCHKE, ob. cit., p. 80-81.

(25) Fausto ZEVI, art. cit., p. 225.

(26) Guilherme CARDoso, art. cit., p. 71. n. ${ }^{\circ} 30$.

(27) A. Coelho-Sonres e C. Tavares da Silva, art. cit., estampa II,

$\left.{ }^{28}\right)$ A. M. Dias Diogo e outros, art. cit., p. 31: os autores confundem este tipo de ânforas com uma bilha de cerâmica comum. 
Os pés apresentam, normalmente, um pequeno furo na parte central inferior.

Foram também encontrados no castelo de Alcácer fragmentos deste tipo, em estratos do séc. $m$ e iv d.C. ${ }^{(29)}$, e no Vale da Cepa $\left({ }^{30}\right)$.

\section{Forma Dressel 38IBeltrán II}

Desta forma apenas nos resta um único fragmento (Fig. 43), encontrado na Herdade do Bugio. Não é de fabrico local, como se pode ver através da pasta, amarela.

Ainda está por explicar a razão pela qual se recorreu à importação e não ao fabrico deste tipo de ânforas próprio paia a salga de peixe numa região como a do Sado, que foi na Antiguidade centro conserveiro.

\section{Forma Almagro 50}

Recolheram-se, desta forma, o fragmento de uma boca (Fig. 19) e fragmentos de pés (Figs. 23, 24, 25 e 26) nos fornos do Pinheiro. Foram também fabricadas nos fornos da Quinta da Alegria ( $\left.{ }^{31}\right)$. Dias Diogo apresenta, no seu trabalho sobre o Vale da Cepa, um fundo de ânfora (n. $\left.{ }^{\circ} 12\right)$ que atribui à forma $51 \mathrm{C}$ mas que nos parece preferível considerar deste tipo. Registou-se ainda a sua presença em estratos dos sécs. $m$ e iv, no castelo de Alcácer ( $\left.{ }^{32}\right)$. Estas ânforas destinar-se-iam a conter pasta de peixe.

(29) Na nota 17 , p. $200-201$.

(30) A. M. Dias Diogo, art. cit., p. 214 (apresentados como sendo do tipo Almagro $51 \mathrm{C})$.

(31) A. Coelho-Sohres e C. Tavares da Silva, art. cit., p. 212.

(32) G. Tavares da Silva e outros, art. cit., p. 200-201. 


\section{Forma Almagro 51 A B C}

Uma boca (Fig. 20) e um pé (Fig. 32), provenientes da Herdade do Pinheiro, são os únicos fragmentos recolhidos das variantes $\mathrm{A}$ e B desta forma.

A variante $\mathrm{C}$ encontra-se representada na Fig. 12, com uma boca muito semelhante à forma lusitana (Fig. 11), só que mais esguia de ombros e em quatro bicos de ânfora (Figs. 14 e 15 dos fornos do Pinheiro e os $n .{ }^{\circ} 51$ e 52 do Bugio).

Foram identificadas ânforas deste tipo na Quinta da Alegria ( ${ }^{33}$ ), em Vale da Cepa ${ }^{(34)}$ e nos estratos do séc. $m$ e iv do castelo de Alcácer.

Fabricaram-se nos fornos do Pinheiro e da Quinta da Alegria algumas formas para as quais não encontramos paralelos nas tabelas tipológicas que conhecemos. As tipologías seguintes são, por essa razão, da nossa responsabilidade.

\section{Forma 91}

Caracteriza-se pelas paredes de pequena espessura, muito bem cozida, com uma boca de lábios espessos, colo curto sobre ombros descaídos (Fig. 16); o bojo é cilíndrico, muito semelhante ao da africana grande, e o pé curto, de duas caneluras (Fig. 27 e 28), características que distinguem esta forma de qualquer outra que conhecemos.

Variantes desta forma consideramos a da Fig. 17, como A, onde o lábio é fino e o ombro mais levantado, e a n. $^{\circ} 19$, como variante $\mathrm{B}$.

Ânforas deste tipo foram encontradas no cemitério tardo-romano de Tróia ${ }^{(36)}$, conjuntamente com africanas grandes. Parker,

(83) A. Coelho-Soares e G. Tavares da Silva, art. cit., p. 213.

(34) A. M. Dias Diogo, art. cit., p. 212.

(35) C. Tavares da Silva e outros, art. cit., p. 200-201.

(36) Devemos à amabilidade do Dr. Francisco Alves, Director do Museu Nacional de Arqueologia e Etnologia, a possibilidade de apresentar neste trabalho o desenho de uma das ânforas aí recolhidas (fig. 53). 
no seu trabalho sobre ânforas lusitanas $\left({ }^{37}\right)$, classifica as ânforas de Tróia como sendo variantes da forma II. Pensamos que terão sido as más condições em que tirou as fotografias $\left({ }^{38}\right)$ e, designadamente, o ângulo escolhido, que não permite reconhecer a forma na sua totalidade, que o induziram em erro.

Aliás, também A. Coelho-Soares e Tavares da Silva classificaram como sendo uma variante das formas Beltrán 56/50 Almagro, os fragmentos que recolheram nos fornos da Quinta da Alegria (39) e na área urbana de Setúbal $\left(^{40}\right)$. Não estão longe da verdade estes autores, pois nós próprios apresentáramos, às III Jornadas Arqueológicas, um homograma que explicava o possível aparecimento desta forma por influência das formas 50 Almagro e 56 Beltrán (africana grande), classificando-a, então, como forma I Pinheiro $\left.{ }^{41}\right)$.

Datamo-la dos séculos $\mathrm{m}$ e iv da nossa era, devido não só à semelhança com as Almagro 50 como também ao contacto, no cemitério de Tróia, com as ânforas de tipo Beltrán 56.

\section{Forma 92}

Distingue-a a existência de uma boca pequena, em funil, com encaixe interno para opérculo (Fig. 29). Aparentada com a forma 51 de Almagro, é de época tardia.

\section{Forma 93}

Caracterizada por uma boca pequena de lábio quadrangular, esta forma apresenta colo curto, em bolsa, com depressão interna muito vincada (Fig. 30). Arranque das asas em fita. Época e conteúdo indefinidos.

(37) Anthony J. PARKe R, obra cit., p. 39.

(38) Anthony J. PARKe R, art. cit., fig. 21.

(3ft) A. Coelho-SonRes e C. Tavares da Silva, art. cit., p.212.

(40) A. Coelho-Sonres e C. Tavares da Silva, art. cit., p.183.

(41) Guilherme CAR Doso, art. cit., mapa da bada do Sado. 


\section{Forma 94}

Será uma ânfora pequena de fundo ovoide (Fig. 31), com pé em botão sulcado na base por um círculo inciso. No Museu do Mar há um pé idêntico, recolhido na praia de Tróia. Época e conteúdo indefinidos.

\section{Opérculos}

Recolhemos dois opérculos completos (Figs. 21 e 22) e vários fragmentos de outros nos fornos da Herdade do Pinheiro, assim como num outro em Abul (Fig. 39). Os do Pinheiro têm diâmetro superior aos de Abul (1i e 9,5 cm, respectivamente) correspondendo ao maior porte das ânforas Dressel 14 fabricadas no Pinheiro.

A pasta é muito grosseira em qualquer deles e as pegas são pequenas saliências que mais serviam para ajudar a encaixar o opérculo do que para o tirar.

\section{CATÁLOGO}

\section{Herdade do Pinheiro}

1. Inv. n. ${ }^{\circ} \mathrm{M}-\mathrm{A} 33$.

Fragmento de boca: lábio perolado, saliente em relação ao colo, que é cilíndrico; asa em fita, com estria exterior vertical.

Dimensões: $12 \times 23 \times 0,8 \mathrm{~cm}$. (*).

Pasta: Vermelha-tijolo, acastanhada, de grão médio, com elementos quartzíticos, micas e xistos.

2. Inv. ${ }^{\circ}{ }^{\circ} \mathrm{M}-\mathrm{A} 35$.

Fragmento de boca: lábio perolado, colo cilíndrico, asa em fita com estria exterior vertical.

Dimensões: 10,5X24X1 cm.

Pasta: Vermelha-tijolo escuro, engobe exterior cinzento, impurezas de quartzito e micas; o interior da pasta apresenta bolhas de ar.

(*) Altura máximaXlargura máximaXespessura das paredes. Os desenhos vão reproduzidos na escala 1:6. 
3. Inv. n. ${ }^{\circ} \mathrm{M}-\mathrm{A} 43$.

Fragmento de asa que é de linhas direitas com dobra em ângulo recto, secção rectangular de ângulos arredondados com estria exterior vertical descentrada. Apresenta, junto ao cotovelo, a marca B.F. Dimensões: $16 \times 6 \mathrm{X} \pm \mathrm{a}, 2 / 2 \mathrm{~cm}$.

Pasta: Castanha clara acinzentada, com elementos de quartzo e mica.

4. Inv. n. ${ }^{\circ} \mathrm{M}-\mathrm{A} 17$.

Boca afunilada: de lábio alto com uma pequena depressão no centro da faixa; colo cónico curto; asas pequenas arredondadas, cujo corte é indeterminável devido ao elevado grau de deterioração. Dimensões: $13 \times 22 \times 0,8 \mathrm{~cm}$.

Pasta: Castanha esbranquiçada; engobe castanho; de grão grosso, com muitas impurezas de quartzo e xisto vermelho escuro.

5. Inv. $.^{\circ} \mathrm{M}-\mathrm{A} 9$.

Fragmento de pé alto, cónico e colo, de forma fálica.

Dimensões: 28,4X6X1 cm.

Pasta: Vermelha-tijolo; engobe castanho avermelhado com partículas de mica branca; de grão fino, com impurezas de quartzo e xisto vermelho.

6. Inv. n. ${ }^{\circ} \mathrm{M}-\mathrm{A} 23$.

Fragmento de pé cónico, oco, de forma fálica.

Dimensões: 14,6X4X1,1 cm.

Pasta: Vermelha-tijolo; de grão médio, com impurezas de quartzo e minúsculos fragmentos de xisto vermelho.

7. Inv. n. ${ }^{\circ} \mathrm{M}-\mathrm{A} 25$.

Fragmento de pé cónico, oco, de forma fálica, a terminar em botão ogival.

Dimensões: $15 \times 6 \times 1 \mathrm{~cm}$.

Pasta: Vermelha-tijolo escuro; engobe exterior vermelho claro; grão médio; impurezas de quartzo e micas.

8. Inv. n. ${ }^{\circ} \mathrm{M}-\mathrm{A} 44$.

Fragmento de pé alto, cónico, oco, com pequena saliência seguida de mamilo na parte inferior, o que é característico desta forma fálica. Tem um $\mathrm{P}$ gravado com estilete, quando a pasta estava mole.

Dimensões: $30 \times 22 \times 0,9 \mathrm{~cm}$.

Pasta: Vermelha-tijolo claro; engobe vermelho escuro; de grão fino, apresentando elementos quartzíticos, micas e xistos. 
9. Inv. n. ${ }^{\circ} \mathrm{M}-\mathrm{A} 20$.

Lábio arredondado, meio cilíndrico, ligeiramente saliente em relação ao colo, que é pequeno, bicóncavo, com várias caneluras exteriores; ombro levantado com pequena inclinação descendente; asas em fita, pequenas, saindo da parte inferior do lábio, arqueadas e com uma secção ligeiramente ovalada, apresentando no exterior um pequeno degrau vertical.

Dimensões: $13 \times 24 \times 0,4 \mathrm{~cm}$.

Pasta: Vermelha-tijolo; de grão médio, com impurezas de quarUo de grandes dimensões e mica branca; há bolhas de ar e fendas no interior.

10. Inv. M-A 11.

Bojo a terminar em ogiva; pé pequeno e oco, com um pequeno orifício central na parte inferior.

Dimensões: $26 \times 27 \mathrm{X} \pm 0,8 / 1,3 \mathrm{~cm}$.

Pasta: Castanha-beige; impurezas quartzíticasleitosas e/ou incolores, micas brancas e pequenas partículas de carvão vegetal; bolhas de ar no interior.

11. Inv. n. ${ }^{\circ} \mathrm{M}-\mathrm{A} 32$.

Lábio alto, cuja forma cónica gera um degrau na ligação ao colo, que é pequeno e cónico estreitando junto ao ombro; asas pequenas, de cotovelos em ângulo recto, secção idêntica à do $\mathrm{n} .^{\circ} 10$.

Dimensões: $16 \times 26 \times 0,9 \mathrm{~cm}$.

Pasta: Castanha-clara; de grão médio, com impurezas de quartzo, micas e xisto; bolhas de ar e fendas no interior.

12. Inv. n. ${ }^{\circ} \mathrm{M}-\mathrm{A} 18$.

Lábio alto, de forma cónica, saliente em relação ao colo, que é pequeno, cónico, estreitando na ligação com o ombro, que por sua vez o apresenta descaído. Asas pequenas, de forma redonda, sem cotovelo saliente, de secção em fita com uma pequena dobra na vertical.

Dimensões: 13,5X21 X0,6 cm.

Pasta: Vermelha-tijolo; grão médio, com impurezas de quartzo e micas brancas. $\mathrm{O}$ interior da pasta tem bolhas de ar.

13. Inv. ${ }^{\circ}{ }^{\mathrm{M}} \mathrm{M}-\mathrm{A} 2$.

Fragmento de pé curto, com vestígios da parte inferior do bojo. Apresenta, na base, um pequeno furo idêntico ao que existe no n. ${ }^{\circ} 10$.

Dimensões: 9,2X12X0,9 cm.

Pasta: Castanha avermelhada clara; grão fino, com impurezas de quartzo e micas brancas; fendas de ar no interior. 
14. Inv. n. ${ }^{\circ} \mathrm{M}-\mathrm{A} 3$.

Fragmento de pé, oco, cónico, de base plana.

Dimensões: 10,4X8,2 X0,8 cm.

Pasta: Vermelha-tijolo, com grão de quartzo e mica branca. O interior da pasta apresenta bolhas de ar e fendas.

15. Inv. . $^{\circ} \mathrm{M}-\mathrm{A} 1$.

Fragmento de pé alto, cónico e oco, base vasada.

Dimensões: $13,4 \times 6,3 \times 0,9 \mathrm{~cm}$.

Pasta: Castanha clara, de grão médio, com impurezas de quartzo e mica branca, mal cozida, com sulcos de torcimento.

16. Inv. $.^{\circ} \mathrm{M}-\mathrm{A} 38$.

Lábio espesso e sobressaído em relação ao colo, que é cónico, curto, estreitando na parte inferior; ombro descaído; asas pequenas, ligeiramente curvadas, arrancando da parte superior do lábio, indo ligar à parte inferior do ombro; a secção é plana, convexa, espessa. Dimensões: 13X18X1,5 cm.

Pasta: Laranja com engobe fino, vermelho; impurezas de quartzo leitoso e mica branca.

17. Inv. n. ${ }^{\circ} \mathrm{M}-\mathrm{A} 36$.

Lábio pequeno, de bordo adoçado; colo liso e cónico afundando na parte inferior; ombro curvilíneo, descaído; asas pequenas, espessas, de forma arredondada.

Dimensões: 16,5X35X0,7 cm.

Pasta: Vermelha-tijolo, clara exteriormente e cinzenta escura no interior; grão fino, com impurezas de quartzo e mica branca.

18. Inv. n. ${ }^{\circ} \mathrm{M}-\mathrm{A} 37$.

Lábio alto, cónico, sobressaindo do colo, que é praticamente inexistente, pois consiste apenas em estreita faixa cilíndrica; ombro descaído, abaulado; asas pequenas, espessas e curvilíneas que ligam, na parte superior, ao colo e ao lábio e, na inferior, ao ombro. Dimensões: 14x30X0,8 cm.

Pasta: Vermelha-tijolo acastanhada; grossa, com impurezas de quartzo leitoso, mica branca e xisto vermelho.

19. Inv. n. ${ }^{\circ}$ M-A 39.

Fragmento de lábio, que se apresenta como aba arredondada, saliente em relação ao colo, com ressalto interno para encaixe do opérculo; do colo só resta a parte superior, cónica; asas de secção achatada, ovoide, arrancando do lábio.

Dimensões: 5X10X1,5 cm.

Pasta: Vermelha-tijolo no exterior e cinzenta no interior; engobe laranja; apresenta impurezas de quartzo e mica. 
20. Inv. n. ${ }^{\circ} \mathrm{M}-\mathrm{A} 31$.

Lábio alto, ligeiramente cónico e saliente em relação ao colo, que é cónico, bastante alto, alargando na parte inferior; das asas só temos o arranque superior, logo abaixo do lábio.

Dimensões: $15 \times 7 \times 0,8 \mathrm{~cm}$.

Pasta: Cinzenta-escura; grossa, com muitas impurezas de quartzo, micas e pequenas partículas de xisto; minúsculas bolhas de ar e fendas no interior.

21. Iriv. n. ${ }^{\circ} \mathrm{M}-\mathrm{A} 41$.

Opérculo completo, discoide, base plana, pega triangular.

Dimensões: 3,5X11X1 cm.

Pasta: Cinzenta escura; grão grosso, com impurezas de quartzo e mica.

22. Inv. n. ${ }^{\circ} \mathrm{M}-\mathrm{A} 42$.

Opérculo completo, forma discoide, de base plana, pega triangular, com um sulco horizontal no bordo do disco.

Dimensões: $4 \times 10,8 \times 1,5 \mathrm{~cm}$.

23. Inv. n. ${ }^{\circ} \mathrm{M}-\mathrm{A} 8$.

Fragmento de pequeno pé, cónico, maciço, com ponta em cabeça ogival.

Dimensões: $7,5 \times 3,5 \times 0,8 \mathrm{~cm}$.

Pasta: Cinzenta escura; grão médio, com impurezas de quartzo, mica e minúsculos fragmentos de xisto; bolhas de ar no interior.

24. Inv. n. ${ }^{\circ} \mathrm{M}-\mathrm{A} 10$.

Fragmento de pequeno pé, cónico, oco, com a ponta em cabeça ogival.

Dimensões: $8,2 \mathrm{X} 4,8 \mathrm{X} 1 \mathrm{~cm}$.

Pasta: Branca acastanhada; grão médio, impurezas de quartzo e grandes partículas de mica.

25. Inv. n. ${ }^{\circ} \mathrm{M}-\mathrm{A} 22$.

Parte inferior de bojo com pé cónico, oco, de ponta em cabeça ogival curta.

Dimensões: 9x7X0,8 cm.

Pasta: Castanha-avermelhada; grão médio, com pequenas impurezas de quartzo e mica branca; fendas de ar no interior.

26. Inv. n. ${ }^{\circ} \mathrm{M}-\mathrm{A} 21$.

Fragmento de pé cónico, de base maciça com ponta em cabeça cónica.

Dimensões: 9x5,6XI cm.

Pasta: Castanha; grão fino, com pequenas impurezas de quartzo e mica. 
27. Inv. n. ${ }^{\circ} \mathrm{M}-\mathrm{A} 5$.

Fragmento de pé pequeno, maciço, com duas caneluras que the dão uma forma em ziguezague característica.

Dimensões: $10,4 \times 5 \times 0,6 \mathrm{~cm}$.

Pasta: Castanha clara; grão médio, com impurezas de xisto vermelho; bolhas de ar no interior.

28. Inv. n. ${ }^{\circ} \mathrm{M}-\mathrm{A} 6$.

Fragmento de pé pequeno semi-oco, de forma oval, na parte superior, e cilíndrica, estreita na inferior.

Dimensões: 8,6X5,9X0,8 cm.

Pasta: Cinzenta clara acastanhada, no exterior, e castanha clara avermelhada no interior; impurezas de quartzo, mica branca e minúsculos fragmentos de xisto vermelho.

29. Inv. n. ${ }^{\circ} \mathrm{M}-\mathrm{A} 29$.

Fragmento de bordo: boca pequena, com rasgo interno para colocação do opérculo; lábio alto, afundado, dando a impressão de não existir; do colo só resta a parte superior, cilíndrica.

Dimensões: 5,8X9,6X0,7 cm.

Pasta: Vermelha clara; grão grosso, com impurezas de quartzo, mica e pequenas partículas de xisto vermelho.

30. Inv. n. ${ }^{\circ} \mathrm{M}-\mathrm{A} 30$.

Fragmento de boca pequena, com uma grande reentrância a meio; lábio pequeno e de secção quadrada, colo repuxado a meio, criando uma bolsa interior; asas com fita.

Dimensões: 8,6X12,8X0,6 cm.

Pasta: Cinzenta escura com veios vermelhos; grão médio, com impurezas de quartzo e minúsculas partículas de mica.

31. Inv. n. ${ }^{\circ} \mathrm{M}-\mathrm{A} 7$.

Bojo em ogiva; pequeno pé em botão com uma estria em círculo na base.

Dimensões: 10,6X16X0,9 cm.

Pasta: Castanha acinzentada; grão médio, com impurezas de quartzo leitoso e mica branca, bolhas de ar no interior.

32. Inv. n. ${ }^{\circ} \mathrm{M}-\mathrm{A} 4$.

Fragmento de pé cónico, esguio.

Dimensões: $7,2 \mathrm{X} 4,3 \mathrm{X} 0,8 \mathrm{~cm}$.

Cinzenta escura acastanhada; impurezas de quartzo leitoso e mica branca; bolhas de ar no interior. 
33. Inv. n. ${ }^{\circ} \mathrm{M}-\mathrm{A} 19$.

Fragmento de pequeno pé, oco, cilíndrico, com duas estrias na parte inferior.

Dimensões: 6X6,8x1 cm.

Pasta: Castanha clara; grão fino, com impurezas de quartzo e mica branca.

Abul

34. Inv. n. ${ }^{\circ} \mathrm{M}-\mathrm{B} 1$.

O lábio é um pequeno bordo adoçado; colo de tipo gola alta, com um ligeiro ressalto na parte inferior; asas em fita, de secção ovoide plana, com canelura exterior vertical.

Dimensões: $25 \times 23 \times 1,1 \mathrm{~cm}$.

Pasta: Castanha escura; grão grosso, com impurezas de quartzo, mica e fragmentos de xisto; bolhas de ar no interior.

35. Inv. n. ${ }^{\circ} \mathrm{M}-\mathrm{B} 3$.

Lábio em pequeno bordo adoçado; colo do tipo gola alta, um pouco mais alta que a anterior.

Dimensões: 23,5X19X1,2 cm.

Pasta: Alaranjada; engobe laranja; grão grosso, com impurezas de quartzo, mica branca e xisto. Bolhas de ar e fendas no interior.

36. Inv. n. ${ }^{\circ} \mathrm{M}-\mathrm{B} 2$.

Do bojo, cilíndrico, só resta a parte inferior; pé cónico, oco, com várias caneluras interiores e exteriores; pequeno grafito feito na pasta ainda mole, em forma de uma seta.

Dimensões: $39 \times 31 \times 1,5 \mathrm{~cm}$.

Pasta: Castanha escura; grão grosso, com impurezas de quartzo, mica e xisto; fendas de ar no interior.

37. Inv. n. ${ }^{\circ} \mathrm{M}-\mathrm{B} 10$.

Fragmento de boca; lábio perolado, com ressalto interno para encaixe de opérculo; do colo resta só a parte superior com arranque de asa.

Dimensões: $6,5 \times 15 \times 1 \mathrm{~cm}$.

Pasta: Castanha clara avermelhada; com impurezas de quartzo e mica; bolhas de ar no interior.

38. Inv. n. ${ }^{\circ} \mathrm{M}-\mathrm{B} 9$.

Colo do tipo gola alta, a que falta a parte superior; asas em fita, com duas estrias paralelas, verticais, exteriores.

Dimensões: $15,5 \times 18 \times 1 \mathrm{~cm}$.

Pasta: Vermelha-tijolo com veios cinzentos; grão fino, com impurezas de quartzo e mica; apresenta bolhas de ar no interior. 
39. ínv. ${ }^{\circ}{ }^{\circ} \mathrm{M}-\mathrm{B} 8$.

Fragmento de opérenlo, de forma discoide com pega triangular. Dimensões: 3X9X1 cm.

Pasta: Castanha acinzentada com manchas vermelhas; grão grosso, com impurezas de quartzo, mica e xisto, bolhas de ar no interior.

40. Ínv. n. ${ }^{\circ} \mathrm{M}-\mathrm{B} 6$.

Fragmento de pé cónico e oco, de base triangular.

Dimensões: $16 \times 12,2 \times 1,4 \mathrm{~cm}$.

Pasta: Laranja com engobe da mesma cor; grão grosso, com impurezas de quartzo e mica fina; fendas de ar no interior.

41. Inv. n. ${ }^{\circ} \mathrm{M}-\mathrm{B} 5$.

Fragmento de pé cónico, oco, de base a terminar em botão ogival. Dimensões: $13 \times 8 X 1,2 \mathrm{~cm}$.

Pasta: Vermelha-tijolo, engobe cinzento, grão grosso, com impurezas de quartzo, mica e xisto; bolhas de ar no interior.

42. Inv. n. ${ }^{\circ} \mathrm{M}-\mathrm{B} 7$.

Fragmento de pé cónico, oco, de forma fálica a terminar em bico. Dimensões: $17,4 \mathrm{X} 12 \mathrm{X} 1,3 \mathrm{~cm}$.

Pasta: Castanha escura; engobe laranja; grão grosso, com impurezas de quartzo, micas brancas e xistos. Apresenta bolhas de ar no interior.

Monte do Bugio

43. Inv. n. ${ }^{\circ} \mathrm{M}-\mathrm{C} 1$.

Fragmento de bordo; lábio voluta.

Dimensões: 6,5X29X1 cm.

Pasta: Branca; grão fino, com impurezas de quartzo e mica.

44. Inv. n. ${ }^{\circ} \mathrm{M}-\mathrm{C} 2$.

Fragmento de boca; resta do lábio um pequeno bordo adoçado; colo do tipo gola alta, de que temos só a parte superior com arranque da asa.

Dimensões: 10X16X1 cm.

Pasta: Vermelha-tijolo; grão grosso, com muitas impurezas de quartzo e micas.

45. Inv. n. ${ }^{\circ} \mathrm{M}-\mathrm{C} 3$.

Fragmento de colo do tipo gola alta, faltando-lhe a parte superior, ombros descaídos.

Dimensões: 20X26X1,5 cm.

Pasta: Vermelha-tijolo; engobe espesso castanho avermelhado; grão grosso, com impurezas de quartzo, mica fina e xisto fino. 
46. Inv. . $^{\circ} \mathrm{M}-\mathrm{C} 10$.

Fragmento de asa, plana, de cotovelo suave, secção em fita com estria vertical exterior.

Dimensões: $14 \times 5 \times 2,5 \mathrm{~cm}$.

Pasta: Vermelha-tijolo; grão médio, com bastantes impurezas de quartzo e mica muito fina.

47. Inv. $.^{\circ} \mathrm{M}-\mathrm{C} 4$.

Fragmento de pé cónico, semi-oco, de forma fálica.

Dimensões: $15 \times 5 \times 1 \mathrm{~cm}$.

Pasta: Vermelha-tijolo; grão médio, contendo impurezas de quartzo e mica.

48. Inv. $.^{\circ} \mathrm{M}-\mathrm{C} 5$.

Parte inferior de pé cónico, semi-oco, com base em bico.

Dimensões: $8,8 \times 4,8 \times 1,3 \mathrm{~cm}$.

Pasta: Laranja; grão grosso, contendo impurezas de quartzo e mica.

49. Inv. n. ${ }^{\circ} \mathrm{M}-\mathrm{C} 6$.

Parte inferior de pé semi-oco.

Dimensões: $7,5 \mathrm{x} 5,8 \mathrm{x}$ ? $\mathrm{cm}$.

Pasta: Vermelha acastanhada; grão médio, contendo impurezas

de quartzo e mica.

50. Inv. n. ${ }^{\circ} \mathrm{M}-\mathrm{C} 9$.

Parte inferior de pé em forma de mamilo.

Dimensões: $7,5 \times 5,2 \times$ ? cm.

51. Inv. n. ${ }^{\circ} \mathrm{M}-\mathrm{C} 7$.

Fragmento de pé cónico, oco, de base plana.

Dimensões: $7,5 \times 7,8 \times 1,2 \mathrm{~cm}$.

Pasta: Cinzenta exteriormente e vermelha no interior; grão médio contendo só impurezas quartzíticas e poucas.

52. Inv. $\mathrm{n}^{\circ} \mathrm{M}-\mathrm{C} 8$.

Fragmento de pé cónico, oco, de base curva.

Dimensões: 7X5,8X 1,2 cm.

Pasta: Laranja; grão grosso, contendo impurezas de quartzo e mica. 
(Página deixada propositadamente em branco) 
Est. I
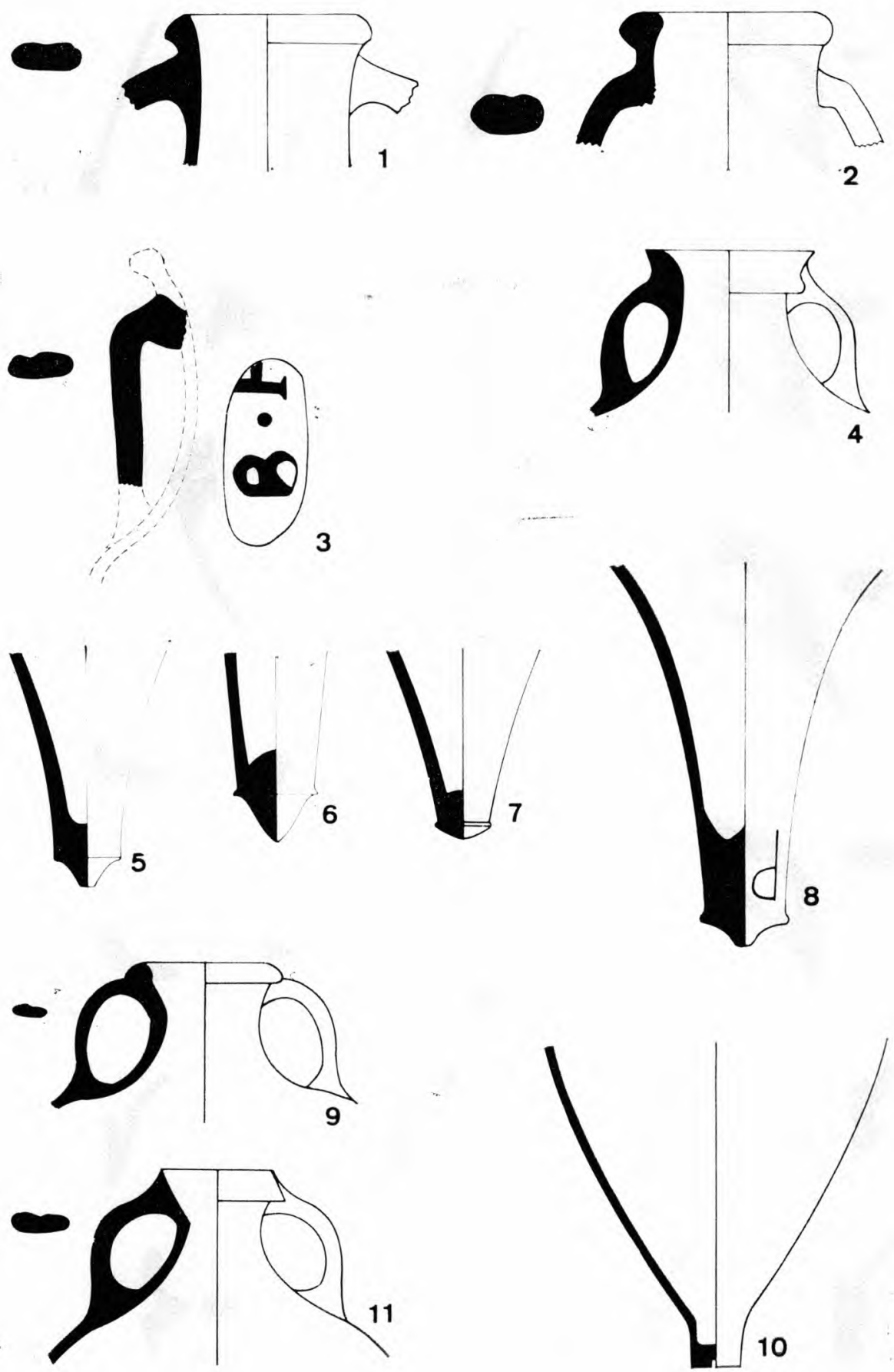
EST. II
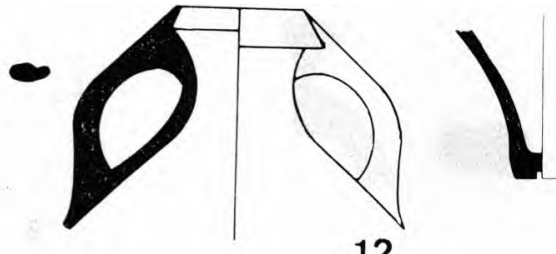

13

12
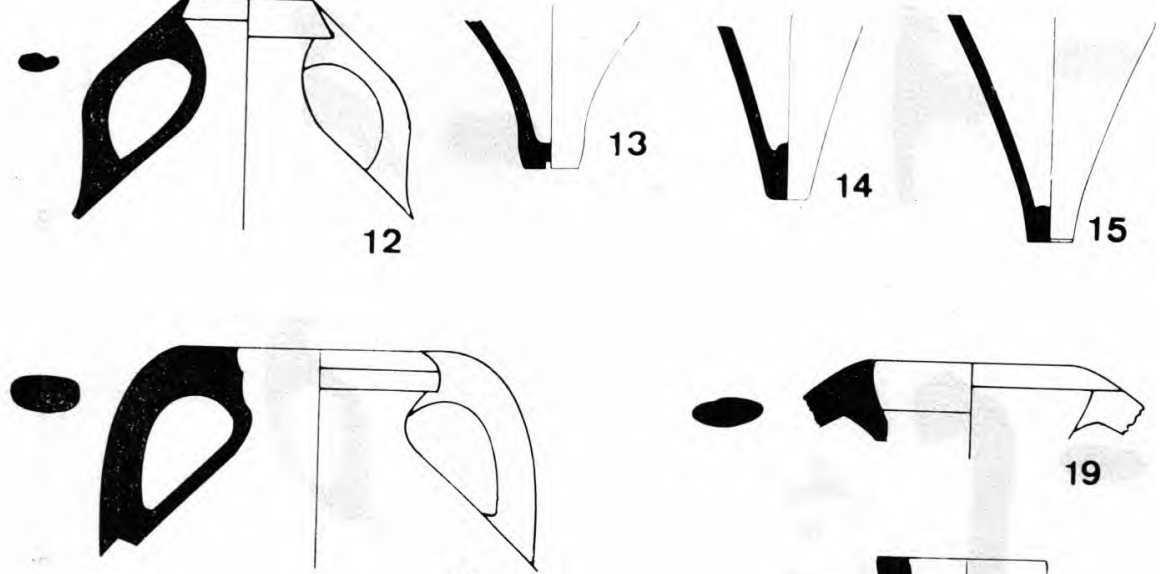

16

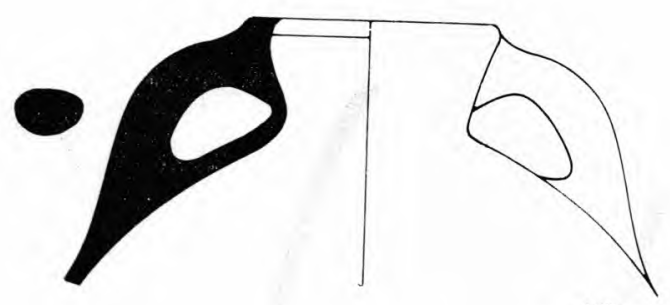

17
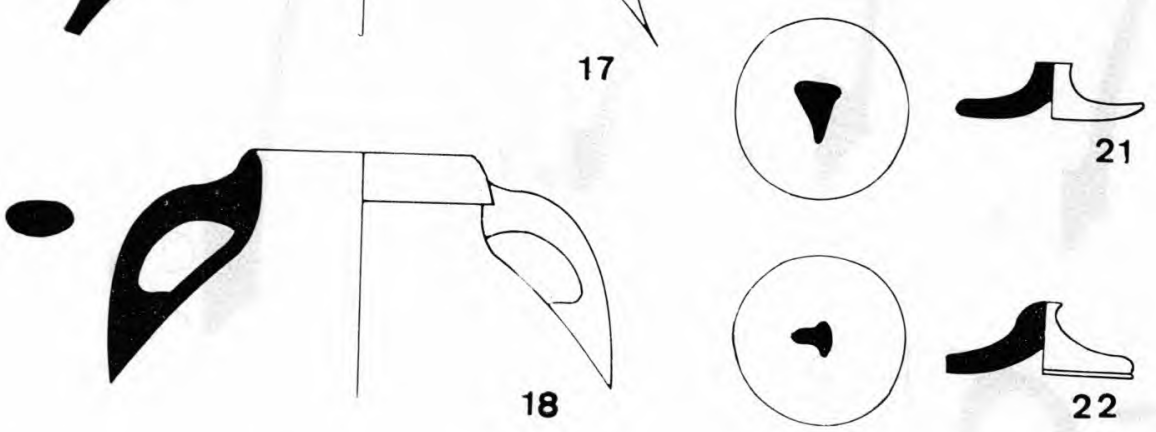

18
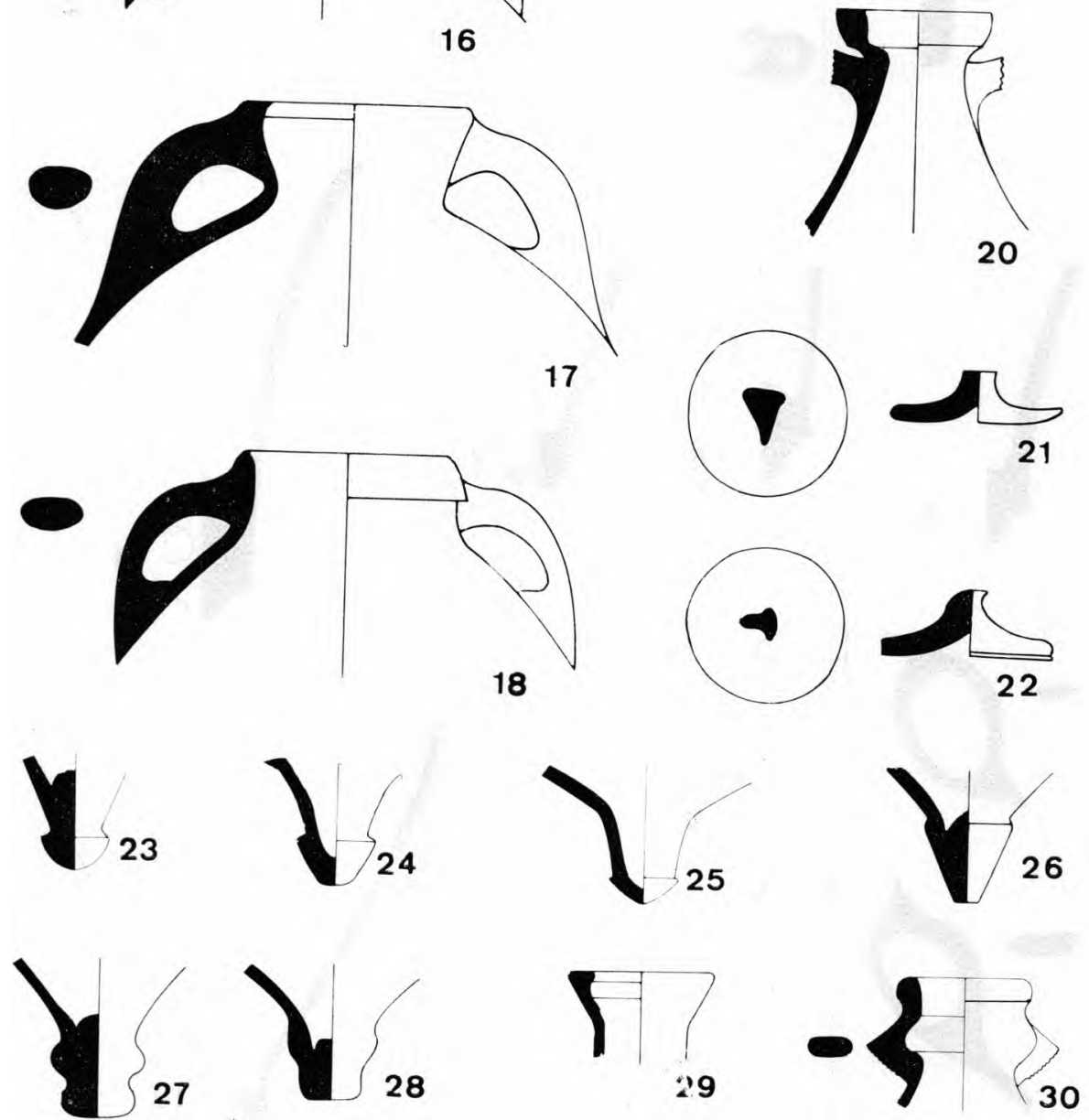
EST. III
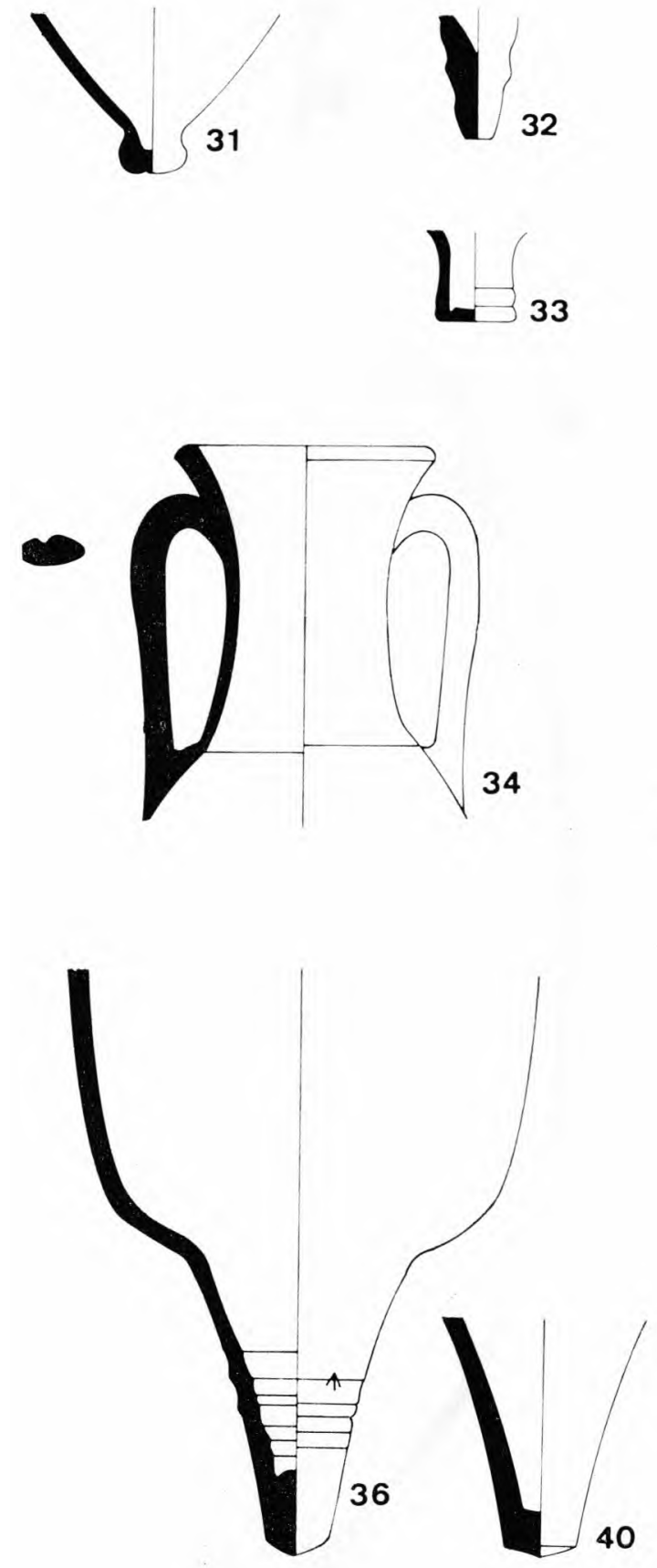
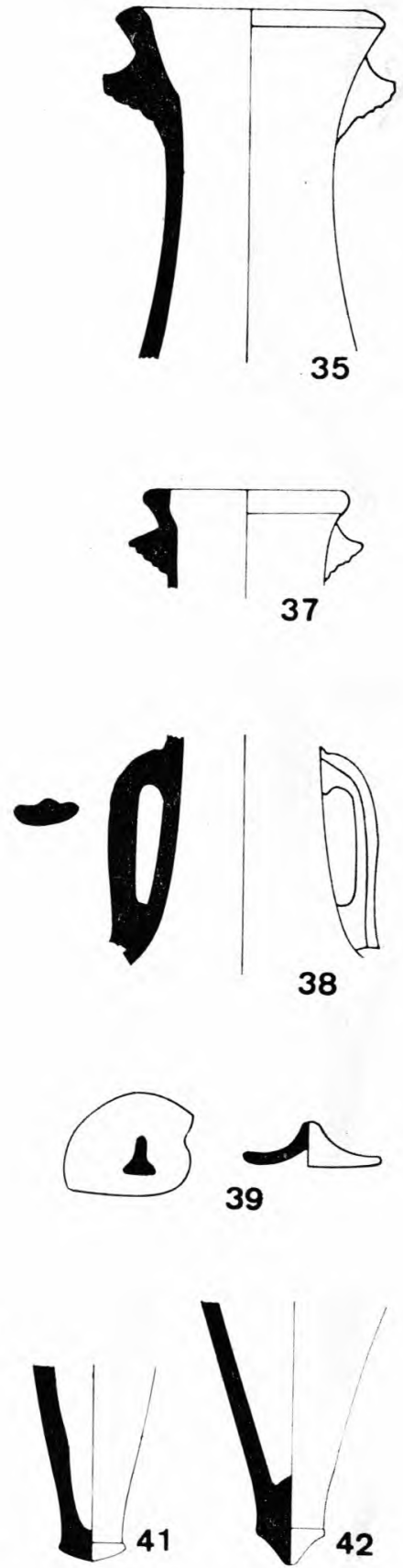


$$
\left.\begin{array}{cc}
1 & 1 \\
1 & -1 \\
1 & 1 \\
1 & 1 \\
1 & 1
\end{array}\right\}^{2}
$$


EST. V

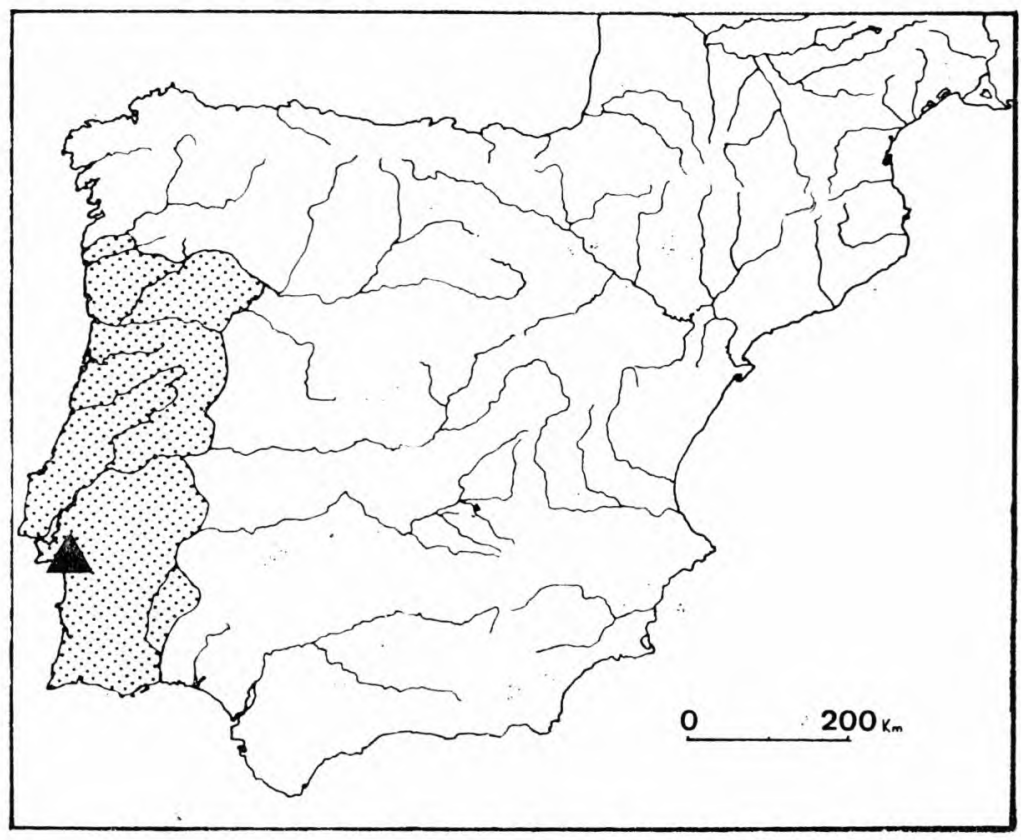

Região da bacia hidrográfica do Rio Sado onde se situam os fornos descritos.

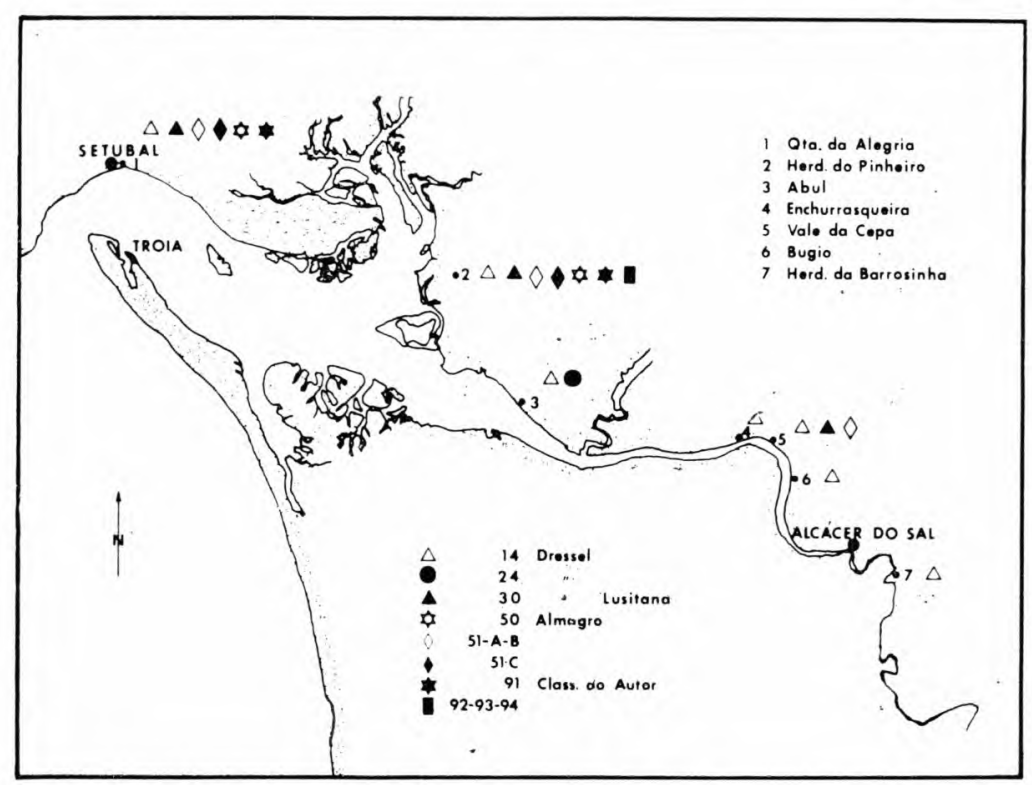

